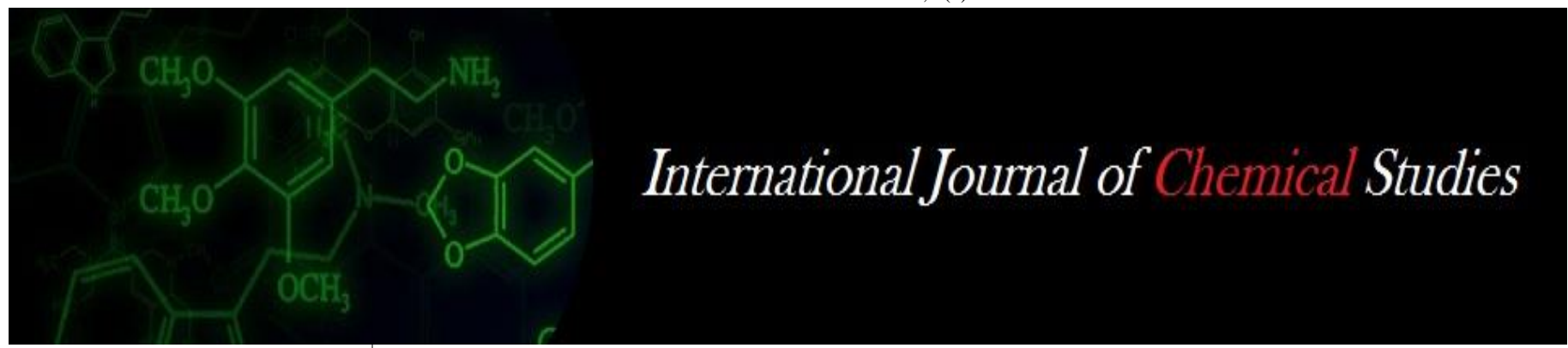

P-ISSN: 2349-8528

E-ISSN: 2321-4902

www.chemijournal.com

IJCS 2021; 9(1): 545-549

(C) 2021 IJCS

Received: 06-10-2020

Accepted: 13-11-2020

Divya Shrivastava

M.Sc. (Ag), Department of Agro-

meteorology, College of

Agriculture, Indira Gandhi

Krishi Vishwavidyalaya, Raipur,

Chhattisgarh, India

Shri JL Chaudhary

Senior Scientist, Department of

Agro-meteorology, College of

Agriculture, Indira Gandhi

Krishi Vishwavidyalaya, Raipur,

Chhattisgarh, India
Corresponding Author: Divya Shrivastava M.Sc. (Ag), Department of Agrometeorology, College of Agriculture, Indira Gandhi Krishi Vishwavidyalaya, Raipur, Chhattisgarh, India

\section{Effect of south-west monsoon onset on rice area in different agro-climatic zones of Chhattisgarh}

\author{
Divya Shrivastava and Shri JL Chaudhary
}

DOI: https://doi.org/10.22271/chemi.2021.v9.i1h.11285

\begin{abstract}
Our current knowledge of the climatic impacts on cropping area is limited. This study investigates the impact of monsoon onset on kharif rice area. There are frequent changes in the Indian summer monsoon. The Indian agriculture is highly vulnerable to any change in south-west monsoon, crop production and crop acreage to be influences by variability of monsoon onset. Fall in the yield leads to shortage of food grains and price rise which affects food security of poor most. This study was carried out to identify impact of SW monsoon onset on acreage of kharif rice at different agro-climatic zones of Chhattisgarh during 1989 to 2017. On the basis of correlation analysis we found that there is positive relationship between onset dates of monsoon and kharif rice acreage. The R-values were 0.136 (In CPZ), 0.06 (In $\mathrm{BPZ}$ ) and 0.122 (In NHZ) for the correlation between monsoon onset dates and rice area. The highest value of correlation co-efficient was found for Chhattisgarh plain zone $(r=0.136)$ which is significant at the $5 \%$ level of significance. In comparison of average rice acreage data under different categories of monsoon onset, we found that late onset conditions are favorable for kharif rice acreage.
\end{abstract}

Keywords: Onset of monsoon, rice area, Correlation

\section{Introduction}

Rainfall is the most variable parameter in time and space of all the normal climatic parameters (Mendelsohn et al., 2001) ${ }^{[4]}$. Rainfall is highly unreliable, both in time and space, with strong risks of dry spells at critical growth stages even during good rainfall years. Inter-annual variations are large due to monsoonal climate-characteristics of atmospheric circulation and strong links to the phenomenon of ENSO in the Pacific Ocean. Many Indian studies have shown similar trends in crop yield decline with climate change (Aggarwal and Mall, 2002) ${ }^{[1]}$. Many studies have indicated that when monsoon rainfall is poor, the output of kharif is low (Krishna Kumar et al., 2004, Mallick et al., 2007) ${ }^{[3,5] .}$

However these studies have mainly concentrated on estimating the climate effect on crop yields. Annual crop production, on the other hand, consists of two additional components other than yield: the harvested area (cropping area) and the number of harvests per year (cropping intensity). However, our current knowledge of the climatic impacts on cropping area and intensity is limited. The latest study by the Intergovernmental Panel on Climate Change (Porter et al., 2014) ${ }^{[6]}$ reminds us of this contrasting situation across the various components of crop production. Undoubtedly a major portion of the increase in crop production in the recent past owes to vast improvements in yield. However, the contribution of cropping area expansion to increased production and export in some regions (Schnepf et al., 2001) ${ }^{[7]}$ should not be underestimated. The practice of agriculture in India begins with the onset of the southwest monsoon. For field preparation and sowing of kharif crops, pre-monsoon rainfall is very important. An analysis of 30 years of data showed a major inter-annual variability in the dates of onset of South-West Monsoon over Chhattisgarh. There is a delayed pattern for the date of monsoon onset over Chhattisgarh after 2004. Therefore, there is need to examine the relationship between onset dates of southwest monsoon and area of kharif rice. The present study used a statistical approach to analyze the impact of variability of south-west monsoon onset on kharif rice area during 1989 to 2017 period. 


\section{Material and Methods}

\subsection{Location of Study Area}

The analysis was carried out with agro climatic zones of Chhattisgarh. The state has three agro climatic zones, the plains of Chhattisgarh, the plateau of Bastar and the region of
Northern hills, spreading over 13.60 million hectares of geographical area. For this study, we have selected three representative stations: Jagdalpur (Bastar Plateau zone), Raipur (Chhattisgarh Plains zone) and Ambikapur (Northern Hill zone).

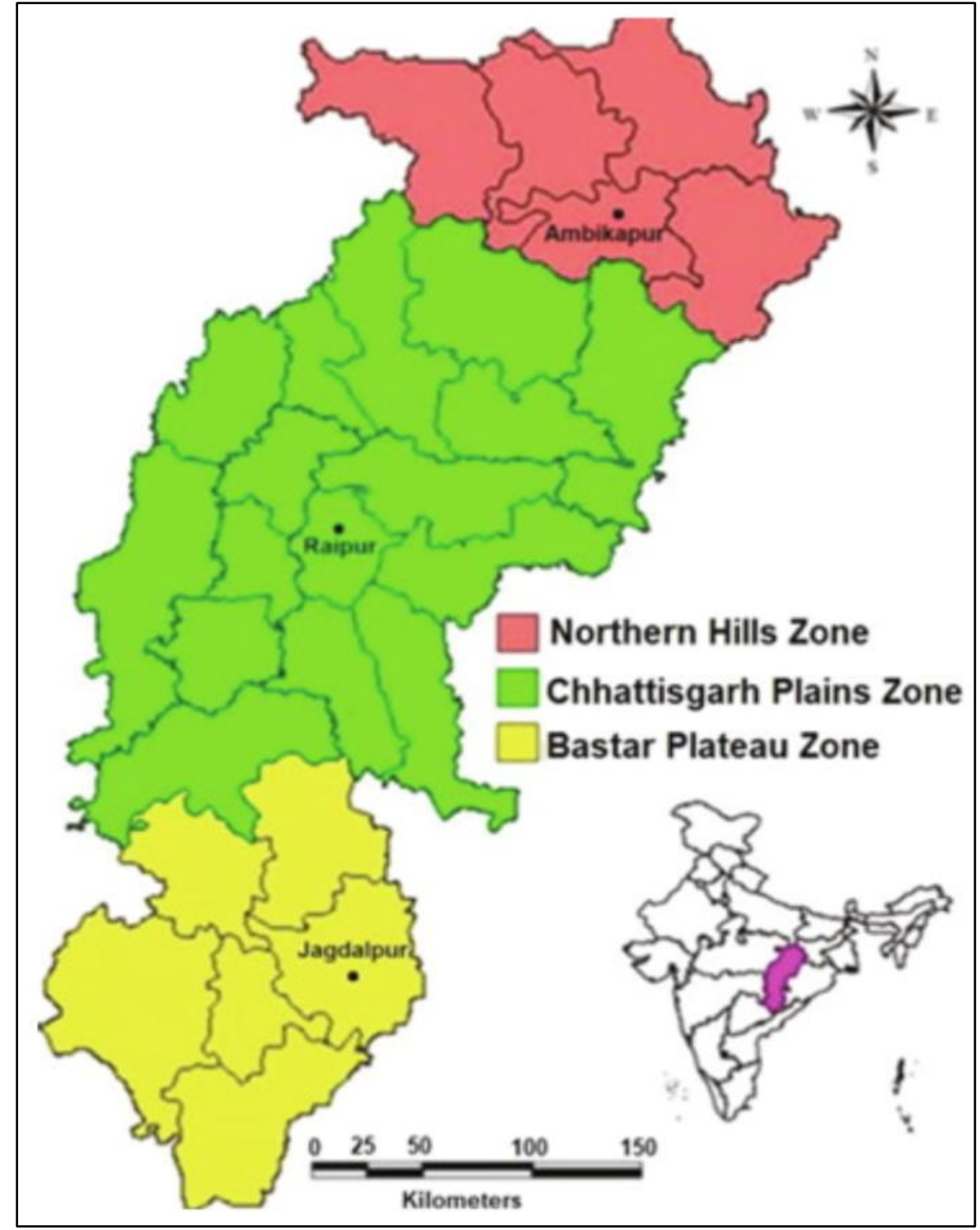

Fig 1: Agro-climatic zones of Chhattisgarh

\subsection{Data set}

The basic data used in the present study are the rice acreage and onset dates of southwest monsoon. Agricultural statistics have been collected from the Ministry of Agriculture. Zone wise monsoon onset data were collected from the Raipur Meteorological Center for the period 1989-2017. The analysis was carried out for the kharif season rice.

\subsection{Methods}

Two methods have been used to examine differences in rice acreage due to variations in onset of monsoon. In the first approach, we compared average rice acreage of 29 years with average rice area of different categories of monsoon onset years. For the categorization of years into the early, normal and late onset year of the monsoon, we used simple statistical methods such as mean and standard deviation.

The mean date of onset of the monsoon was calculated by using the equation as shown below:
$\bar{X}=\frac{\left(\sum x_{i}\right)}{n}$

\section{Where}

$x i=$ dates of onset of effective monsoon.

$\mathrm{n}=$ Total number of years.

The standard deviation of $\boldsymbol{x i}$ dates of onset of monsoon as computed by using the following equation.

Standard deviation $=\frac{\sqrt{\Sigma(\mathrm{x}-\overline{\mathrm{x}})^{2}}}{\mathrm{n}-1}$

\section{Where}

$\overline{\mathrm{X}}=$ Mean onset date

$\mathrm{n}=$ Number of years

$\mathrm{x}=$ Actual onset date

In the second process, we used simple correlation method to examine the impact of onset of monsoon on rice acreage. 


\subsection{Correlation co-efficient}

Correlation is a statistical method that can demonstrate whether and how strongly pairs of variables are associated with each other. It indicates the extent to which two or more variable fluctuate together. It is used to explain the linear relationship between two continuous variables.

$\mathrm{r}=\frac{n(\Sigma \mathrm{xy})-(\Sigma \mathrm{x})(\Sigma \mathrm{y})}{\sqrt{\left[n \Sigma \mathrm{x}^{2}-(\Sigma \mathrm{x})^{2}\right]\left[n \Sigma \mathrm{y}^{2}-(\Sigma \mathrm{y})^{2}\right]}}$

\section{Results}

\subsection{Effect of monsoon onset in different agro-climatic zone} Bastar plateau zone

The average values (1989-2017) of rice acreage is calculated and summarized in Table 1. The effect of onset of monsoon on paddy production has been analyzed from the Table 2 . It has been seen that in late onset years of monsoon, there is significant indication of increased rice area compared to the 29 -year average value of rice acreage. Rice acreage in early monsoon onset years is 604.6 thousand ha while it is 631.6 thousand ha in normal years hence it can be easily interpreted that there is a $4.5 \%$ percent increase in average rice acreage in late onset years of monsoon. However in this tribal belt due to early onset of monsoon, average paddy area has come down to 604.6 thousand ha which is $2.4 \%$ lower than average value (619.4 thousand ha). If we see the rice acreage in normal onset years (621.68 thousand ha) it is very close to average figure of 29 year average value (619.4 thousand ha). As a result, it can be seen that there is some advantage to the farmers in late monsoon onset years, and paddy crop acreage increased positively to 631.6 thousand ha.

\subsubsection{Chhattisgarh plain zone}

During the study period the average acreage of rice in late onset years is 2852.8 thousand ha while it is 2803.5 thousand ha in normal onset years and 2788.7 thousand ha in early onset years.

If we see the rice acreage in late onset years it is significantly touching an average figure of 2852.8 thousand ha which is $2.3 \%$ higher than average value of early onset years $(2788.7$ thousand ha). On the other hand early onset of monsoon is having its unfavorable impact on rice area. This leads to interpretation that farmers are not able to make use of the early onset of monsoon.

\subsubsection{Northern hill zone}

It can be interpreted from the study that the effect of the late onset of monsoon on paddy acreage in the Northern Hill Region is favorable and that paddy area appears to be increased in the late onset condition. Area in early monsoon onset years is 367.8 thousand ha while it is 368.3 thousand ha in normal years. In late onset conditions it can be very well seen that there is advantages in rain-fed paddy cultivation area with rice acreage of 382.9 thousand ha. This value is $4.19 \%$ more than the average value of early monsoon onset years. It has been observed that in normal onset of monsoon, rice area has not increased and it has remained at nominal level. Detailed analysis for understanding this difference of rice acreage among different ACZ needs to be undertaken.

Table 1: Zone wise average area (1989-2017) of kharif rice in different ACZ of C.G.

\begin{tabular}{|c|c|c|}
\hline Zone & Year & Area (thousand ha) \\
\hline N.H.Z & $1989-2017$ & 370.2 \\
\hline C.P.Z. & $1989-2017$ & 2809.5 \\
\hline B.P.Z & $1989-2017$ & 619.4 \\
\hline
\end{tabular}

Table 2: Average acreage of kharif Rice according to early, normal and late 'onset' years of monsoon for different ACZ

\begin{tabular}{|c|c|}
\hline \multicolumn{2}{|c|}{ For Northern Hill zone } \\
\hline Categories & Area (thousand ha) \\
\hline Average rice acreage in Normal onset year & 368.3 \\
\hline Average rice acreage in Early onset year & 367.8 \\
\hline Average rice acreage in Late onset year & 382.9 \\
\hline \multicolumn{2}{|c|}{ For Chhattisgarh plain zone } \\
\hline Categories & Area (thousand ha) \\
\hline Average rice acreage in Normal onset year & 2803.5 \\
\hline Average rice acreage in Early onset year & 2788.7 \\
\hline Average rice acreage in Late onset year & 2852.8 \\
\hline \multicolumn{2}{|c|}{ For Bastar plateau zone } \\
\hline Categories & Area (thousand ha) \\
\hline Average rice acreage in Normal onset year & 621.6 \\
\hline Average rice acreage in Early onset year & 604.6 \\
\hline Average rice acreage in Late onset year & 631.6 \\
\hline
\end{tabular}

\subsection{Correlation analysis}

In this study, the correlation analysis has been undertaken to find out the relationship between the monsoon onset and rice acreage in different A.C.Z. of Chhattisgarh. Table 3 shows the values of correlation co-efficient between onset dates and paddy acreage. Correlation coefficients are 0.245 (for B.P.Z.), 0.369 (for C.P.Z.) and 0.350 (for N.H.Z.). From the analysis it is observed that there is significant relationship between monsoon onset dates and paddy acreage in Chhattisgarh plain zone.

The relationship between onset dates of monsoon and paddy acreage has been seen from the Fig 2, 3 and 4. A positive correlation has been seen in all three agro-climatic zones between the onset of the south-western monsoon and the rice acreage. The highest value of correlation co-efficient was found for Chhattisgarh plain zone $(r=0.369)$. This value is significant at the $5 \%$ level of significance for onset dates of SWM and rice acreage during 1989-2017. Therefore it can be said that there are significant effect on rice area due to variability of monsoon onset.

Table 3: Correlation co-efficient ( $\mathrm{r}$ ) of rice acreage and onset dates of SWM

\begin{tabular}{|c|c|}
\hline Agro-climatic zones & Correlation co-efficient \\
\hline NHZ & 0.350 \\
\hline CPZ & $0.369^{*}$ \\
\hline BPZ & 0.245 \\
\hline
\end{tabular}




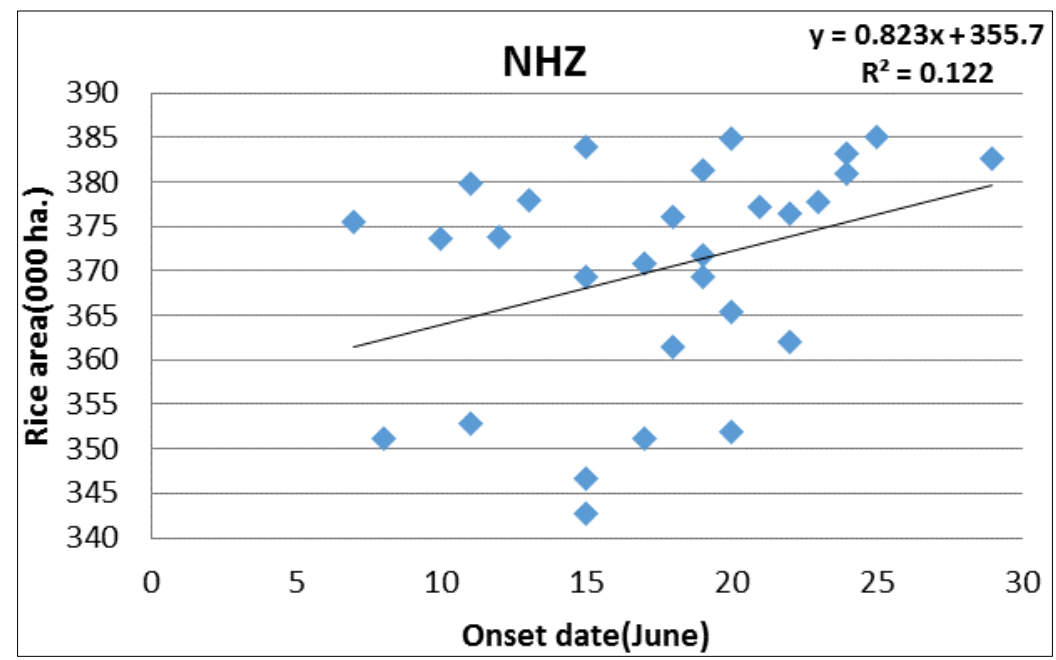

Fig 1: Correlation between onset dates of monsoon and rice area in NHZ

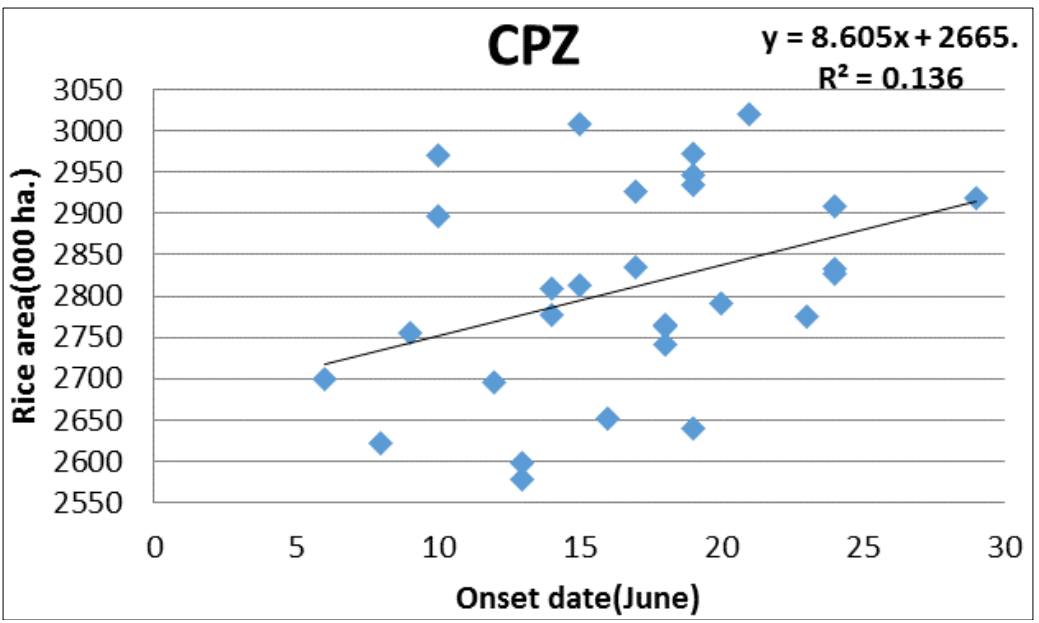

Fig 2: Correlation between onset dates of monsoon and rice area in CPZ

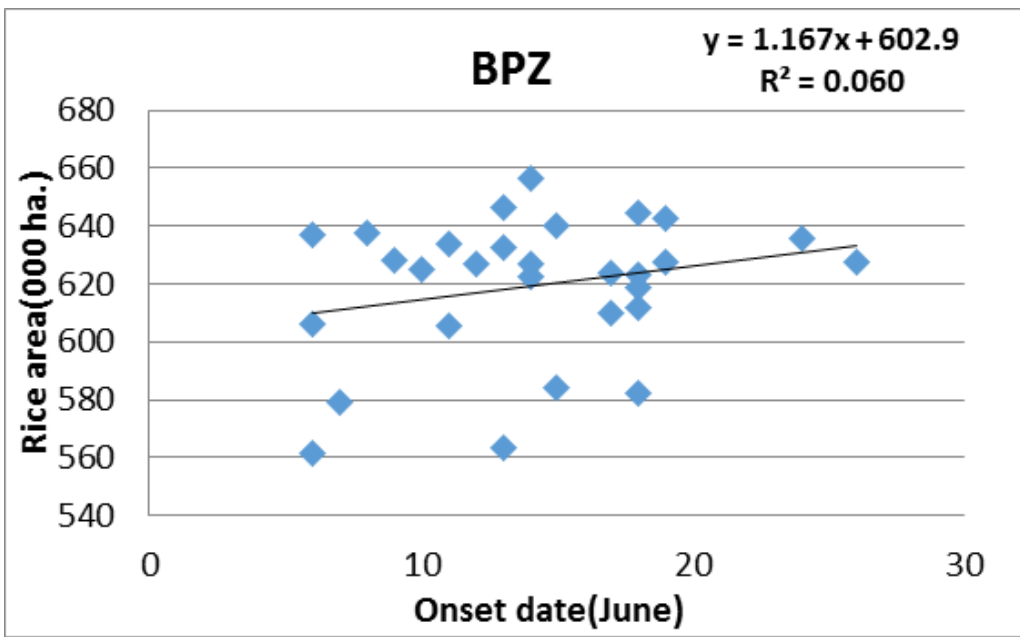

Fig 3: Correlation between onset dates of monsoon and rice area in $\mathrm{BPZ}$

\section{Discussion and Conclusion}

The date of onset and withdrawal of the southwest monsoon in Chhattisgarh is very important for farmers as it affects the timing of crop sowing and the length of the southwest monsoon season. Comparing average rice acreage data for different categories of monsoon onset, we found that late monsoon onset conditions are favorable for rice acreage. Based on the correlation study, we found that there is a significant association between the date of onset of monsoon and the acreage of rice. Iizumi and Ramankutty analyzed the effects of weather and climate on cropping area and intensity. They conclude by discussing important knowledge gaps that need to be addressed in future research and potential ways for moving forward. Climate and weather influences cropping area, intensity and yield in different ways. Improving our knowledge of climate influences on and management contributions to cropping area and intensity as well as yield is important to reduce the uncertainty of future climate change impacts on crop production and develop more targeted climate adaptation responses. It may facilitate the 
development of strategies to deal with the influence of rainfall variability, floods, and hail storms on cropping systems. In our previous research, we found that there was a delayed trend of monsoon onset over Chhattisgarh after 2004. All these changes have an effect on the cropping pattern, crop growth, area and yield of rice. Therefore, intensive research should be required to highlight the relationship between monsoon onset and rice acreage.

\section{References}

1. Aggarwal PK, Mall RK. Climate change and rice yields in diverse agro-environments of India. II. Effect of uncertainties in scenarios and crop models on impact assessment. Climate Change 2002;52(3):331-343.

2. Iizumi T, Ramankutty N. How do weather and climate influence cropping area and Intensity. Global Food Security 2015;4:46-50

3. Krishna Kumar K, Rupa Kumar K, Ashrit RG, Deshpande NR, Hansen JW. Climate impacts on Indian agriculture. Int. J. Climatol 2004;24:1375-1393.

4. Mendelsohn RA, Dinar A, Sanghi. The effect of development on the climate sensitivity of agriculture, Environment and Development Economics 2001;6:85101.

5. Mallick K, Mukherjee J, Bal SK, Bhalla SS, Hundal SS. Real time rice yield forecasting over central Punjab region using crop weather regression model. J Agrometeorol 2007;9:158-166.

6. Porter JR, Xie L, Challinor AJ, Cochrane K, Howden M, Iqbal MM et al. Food security and food production systems. Climate Change: Impacts, Adaptation, and Vulnerability. Cambridge University Press, Cambridge 2014,485-533p.

7. Schnepf RD, Dohlman E, Bolling C. Agriculture in Braziland Argentina: Developments and Prospects for Major Field Crops 2001. (http://www.ers.usda.gov/ publications/wrs-international-agriculture-and-tradeoutlook/wrs013.aspx) 